\title{
Morfologia e ultraestrutura de arcos branquiais de juvenis de Mugil platanus Günther (Pisces, Mugilidae)
}

\author{
José Claro da Fonseca Neto ${ }^{1,2}$ \\ Henry Louis Spach ${ }^{1}$
}

\begin{abstract}
Gill arch surface morphology and ultrastructure of juvenile Mugil platanus Günther (Pisces, Mugilidae). Scanning electron microscopy revealed that the gill arch surface from juveniles of Mugil platanus Günther, 1880 is similar to that reported for others euryhaline teleosts. Two filament rows (about 41-49 filament per row) extend posteriorly, and two rows of rakers (about 42-46 rakers per row) extended anteriorly from each arch. Respiratory lamellae protrude along both sides of each filament $(37 / \mathrm{mm})$, from the base to the apex. The distribution, sizes and structure of various surface cells were also described. Except for the respiratory lamellae, the surface of whole gill arch is covered by a mosaic of pavement cells, which measure about $6,94 \mathrm{X} 4,61 \mu \mathrm{m}$ and exhibit concentrically arranged surface ridges. The anterior pharyngeal surfaces of the raker of the first arch and the ventral part of the second, smooth secondary projections are present which are replaced by spiny secondary projections on the dorsal part of the second arch, and entire third and fourth arches. Taste buds are especially prominent between smooth projections. Apical crypts of chloride cells occur mostly at the afferent surface of the gill filament.

KEY WORDS. Gill arch, Mugil platanus, morfology, surface ultrastructure
\end{abstract}

As brânquias dos teleósteos são morfologicamente muito semelhantes, com algumas variações em função do modo de vida, hábito alimentar e habitat do peixe (GRAY 1954; HuGHES 1966), bem como por fatores filogenéticos (SCHMIDT-NIELSEN 1990).

Dois tipos de epitélios podem ser distinguidos pela anatomia, desenvolvimento embrionário, vascularização e ultraestrutura dos componentes celulares. Cobrindo praticamente todo o arco branquial, inclusive os rastelos, filamentos e região interlamelares, encontra-se o epitélio primário pluriestratificado, composto por diferentes tipos celulares, incluindo as células pavimentosas, células secretoras de muco, botões gustativos, células de cloro e células de suporte (DUNEL-ERB \& LAURENT 1980; LAURENT 1984). As lamelas respiratórias são cobertas pelo epitélio secundário biestratificado com células pavimentosas na camada externa e células indiferenciadas na camada interna (LAURENT \& DUNEL 1980).

Este trabalho, tem por objetivo descrever a morfologia e a ultraestrutura superficial do arco branquial de juvenis de Mugil platanus Günther, 1880.

1) Centro de Estudos do Mar, Universidade Federal do Paraná. Avenida Beira Mar, $83255-000$ Pontal do Paraná, Paraná, Brasil.

2) Curso de Pós-graduação em Zoologia, Departamento de Zoologia, Universidade Federal do Paraná. Caixa Postal 19020, 81531-990 Curitiba, Paraná, Brasil. 


\section{MATERIAL E MÉTODOS}

Os juvenis de $M$. platanus utilizados neste trabalho, apresentaram comprimentos totais entre 28 e $33 \mathrm{~mm}$ e foram capturados no verão de $1995 \mathrm{em}$ valos situados na praia de Pontal do Sul, Paraná, utilizando-se para tal uma rede do tipo picaré com 7,0x2,0 $\mathrm{m}$ e malha de $1 \mathrm{~mm}$.

Sob microscópio estereoscópico, os arcos branquiais de exemplares fixados em formol $4 \%$ e preservados em álcool $70 \%$, foram retirados e separados para a descrição da morfologia branquial. Contagens do número de rastelos e filamentos foram realizadas somente no segundo arco branquial esquerdo e direito e o número de lamelas por milímetro, foram contadas nos filamentos da região mediana do segundo arco branquial esquerdo. Com o objetivo de testar a hipótese de que o número de rastelos e filamentos é igual tanto no segundo arco branquial esquerdo como no direito e em suas regiões medial e lateral, foram utilizadas as análises de variância uni e bi-fatorial. $\mathrm{Na}$ análise de variância bi-fatorial foram considerados fatores fixos o posicionamento do arco (arco direito e arco esquerdo) e a região num mesmo arco (medial e lateral). $\mathrm{Na}$ análise de variância uni-fatorial o fator fixo utilizado foi o posicionamento junto com a região (arco direito medial e lateral, arco esquerdo medial e lateral). Uma vez observadas diferenças significativas $(\mathrm{P}<0.05)$ utilizou-se o teste de comparação múltipla de Scheffé (SNEDECOR \& COCHRAN 1980).

Para as observações em microscópio eletrônico de varredura (MEV), os peixes foram mortos por decapitação e os arcos branquiais foram retirados da cavidade opercular e lavados em soluções de Curtland ou de $\mathrm{NaCl} 0,9 \%$. Em seguida, o segundo arco branquial esquerdo foi cuidadosamente destacado e fixado por 24 horas a uma temperatura de 4 a $5^{\circ} \mathrm{C}$ em uma solução preparada a fresco de glutaraldeído $3 \%$ tamponado em solução de calcodilato de sódio $0,2 \mathrm{M}(\mathrm{pH} 7.2)$. Após o período de fixação, o arco branquial foi submetido a três lavagens de um minuto cada com água destilada. Em seguida, foi transferido para álcool $50 \%$ onde foi deixado durante 15 minutos, sendo posteriormente conservado em álcool $70 \%$ a uma temperatura de 4 a $5^{\circ} \mathrm{C}$. No momento da preparação para o $\mathrm{MEV}, \mathrm{o}$ arco foi sucessivamente transferido para o álcool $90 \%$ e duas secções de álcool absoluto, sendo mantido por 15 minutos em cada uma destas concentrações, desidratado com $\mathrm{CO}_{2} \mathrm{em}$ um aparelho de ponto crítico, modelo Balzers CPD-010, montado em suporte de alumínio e metalizado em um aparelho Balzers, modelo SCD-030. As observações e fotomicrografias foram feitas em microscópio eletrônico de varredura Phillips modelo SEM 505 e JEOL JSM 840a.

\section{RESULTADOS}

\section{Descrição geral do arco branquial}

A morfologia dos arcos branquiais de $M$. platanus é similar à observada em outros mugilideos (GRAY 1954). Quatro pares de arcos branquiais (ABI a ABIV) estão inseridos no sentido ântero-posterior em cada lado da cavidade faringeal. Cada arco branquial suporta duas fileiras de rastelos e duas fileiras de filamentos (hemi- 
brânquias), situadas respectivamente, ao longo das regiões anterior e posterior do arco. Vistos lateralmente, os arcos tem a forma de "C", com a região medial ligeiramente côncava e a região lateral ligeiramente convexa. Na região dorsal observa-se a presença de uma curvatura que diminui gradativamente do $\mathrm{ABI}$ para o ABIV. Os três primeiros arcos são similares em tamanho, sendo o ABII ligeiramente maior e o ABIV é o menor de todos (Figs 1-2).

\section{Descrição geral dos rastelos branquiais}

Os rastelos branquiais diferem no comprimento e na morfologia de um arco branquial para outro e entre a região dorsal e a ventral de um mesmo arco. Na porção mediana dos ABI, II e III os rastelos da fileira associada a região lateral do arco são maiores que os rastelos da fileira associada a região medial. Nas extremidades e na região medial do ABI, II e III, e em ambas as fileiras do ABIV, estão presentes rastelos de tamanho reduzido. De maneira geral os rastelos apresentam-se achatados com contorno triangular a trapezóide. Na borda da região anterior dos rastelos, estão presentes duas séries de projeções secundárias, com a forma variando entre os rastelos, sendo que no $\mathrm{ABI}$ e na região ventral do $\mathrm{ABII}$, apresentam-se como projeções lobulares simples e na região mediana dorsal do ABII e em todo o ABIII e IV, modificam-se para formas mais complexas, apresentando extremidades ramificadas de onde partem pequenas estruturas com formato de ponta (Figs 3-6).

O número de rastelos da região medial é significativamente maior que o da região lateral, porém entre o $\mathrm{ABII}$ esquerdo e direito, não foi constatada diferença significativa no número de rastelos quando comparadas as mesmas regiões (Tabs I-II).

Tabela I. Média e desvio padrão do número de filamentos e rastelos branquiais de juvenis de Mugil platanus, $(n=30)$. Resultados da análise de variância uni-fatorial e teste de comparação múltipla de Scheffé. Grupos sem diferenças significativas encontram-se no mesmo parênteses. (E) Arco esquerdo, (D) arco direito, (M) região medial, (L) região lateral.

\begin{tabular}{|c|c|c|c|c|c|c|}
\hline \multirow{2}{*}{ Estrutura } & \multicolumn{2}{|c|}{ Arco esquerdo } & \multicolumn{2}{|c|}{ Arco direito } & \multirow{2}{*}{$\mathrm{F}$} & \multirow{2}{*}{ Grupos } \\
\hline & Região medial & Região lateral & Região medial & Região lateral & & \\
\hline Filamento & $41,67(2,89)$ & $49,63(3,27)$ & $40,93(2,57)$ & $49,37(4,31)$ & $\underset{\star}{60,99}$ & $\begin{array}{c}\text { (EM,DM) } \\
(E L, D L)\end{array}$ \\
\hline Rastelo & $45,87(3,51)$ & $41,97(3,70)$ & $45,53(2,67)$ & $42,23(2,99)$ & $\underset{*}{12,40}$ & $\begin{array}{c}\text { (EM,DM) } \\
\text { (EL,EL) }\end{array}$ \\
\hline
\end{tabular}

$\left.{ }^{\star}\right) p<0.01$.

Tabela II. Resultados da análise de variância bi-fatorial, avaliando a influência do posicionamento dos ABII (direito e esquerdo) e das diferentes regiões (medial e lateral) sobre o número de filamentos e rastelos do ABII de juvenis de Mugil platanus. (NS) Diferença não significativa, (M) medial, (L) lateral.

\begin{tabular}{lccc}
\hline Estrutura & Variações entre arcos & Variações entre regiões & $\begin{array}{l}\text { Variações entre arcos } x \\
\text { variações entre regiões }\end{array}$ \\
\hline Filamento & NS & $M<L^{*}$ & $N S$ \\
Rastelo & NS & $M>L^{*}$ & $N S$ \\
\hline
\end{tabular}

*) $p<0.01$. 


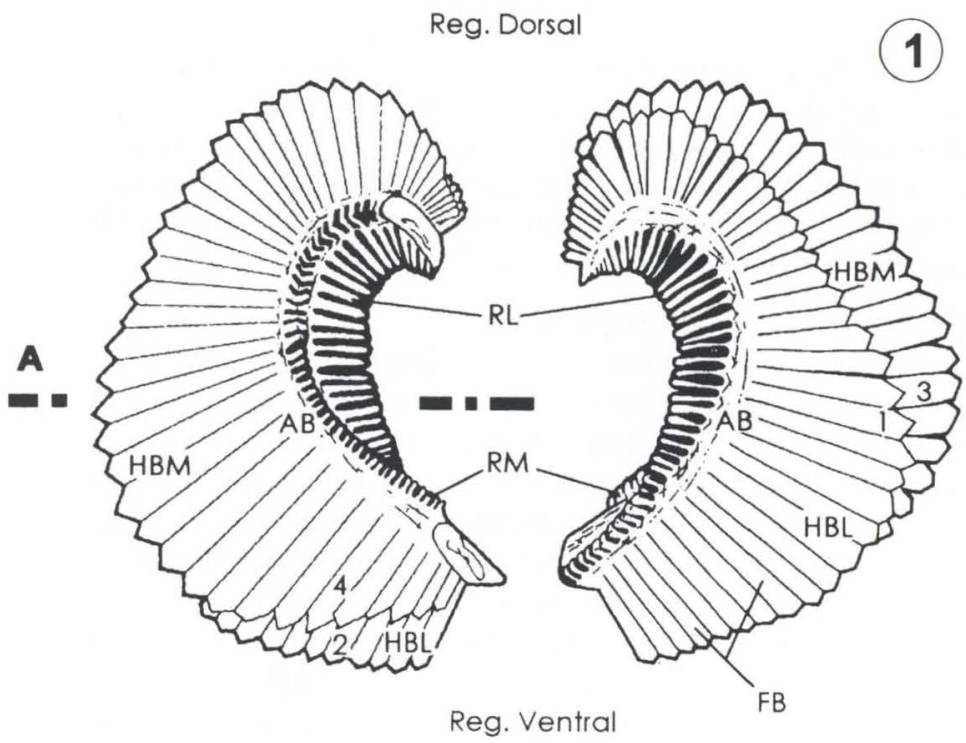

VISTA DA REGIÃO MEDIAL VISTA DA REGIÃO LATERAL

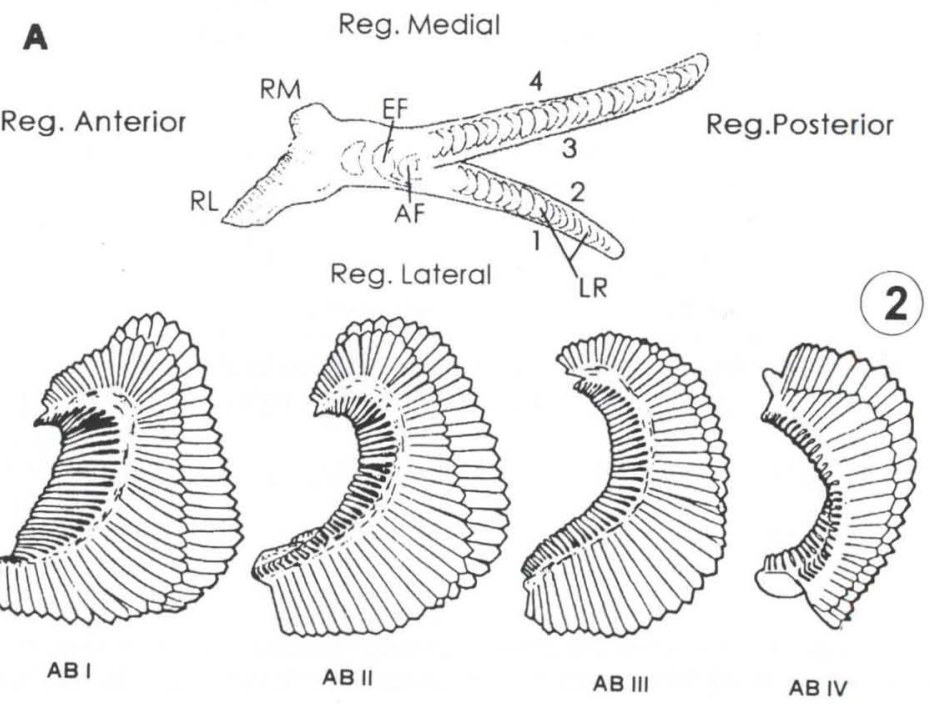

Figs 1-2. (1) Esquema das estruturas do segundo arco branquial esquerdo (ABII) e de um corte transversal do mesmo arco (A); (2) arcos branquiais esquerdos de um juvenil de Mugil platanus de $34 \mathrm{~mm}$. (AB) arco branquial, (FB) filamento branquial, (RL) rastelos laterais, (RM) rastelos mediais, (HBL) hemibrânquia lateral, (HBM) hemibrânquia medial, (AF) artéria branquial aferente, $(E F)$ artéria branquial eferente, (LR) lamlelas respiratórias. Barra $1 \mathrm{~mm}$. 

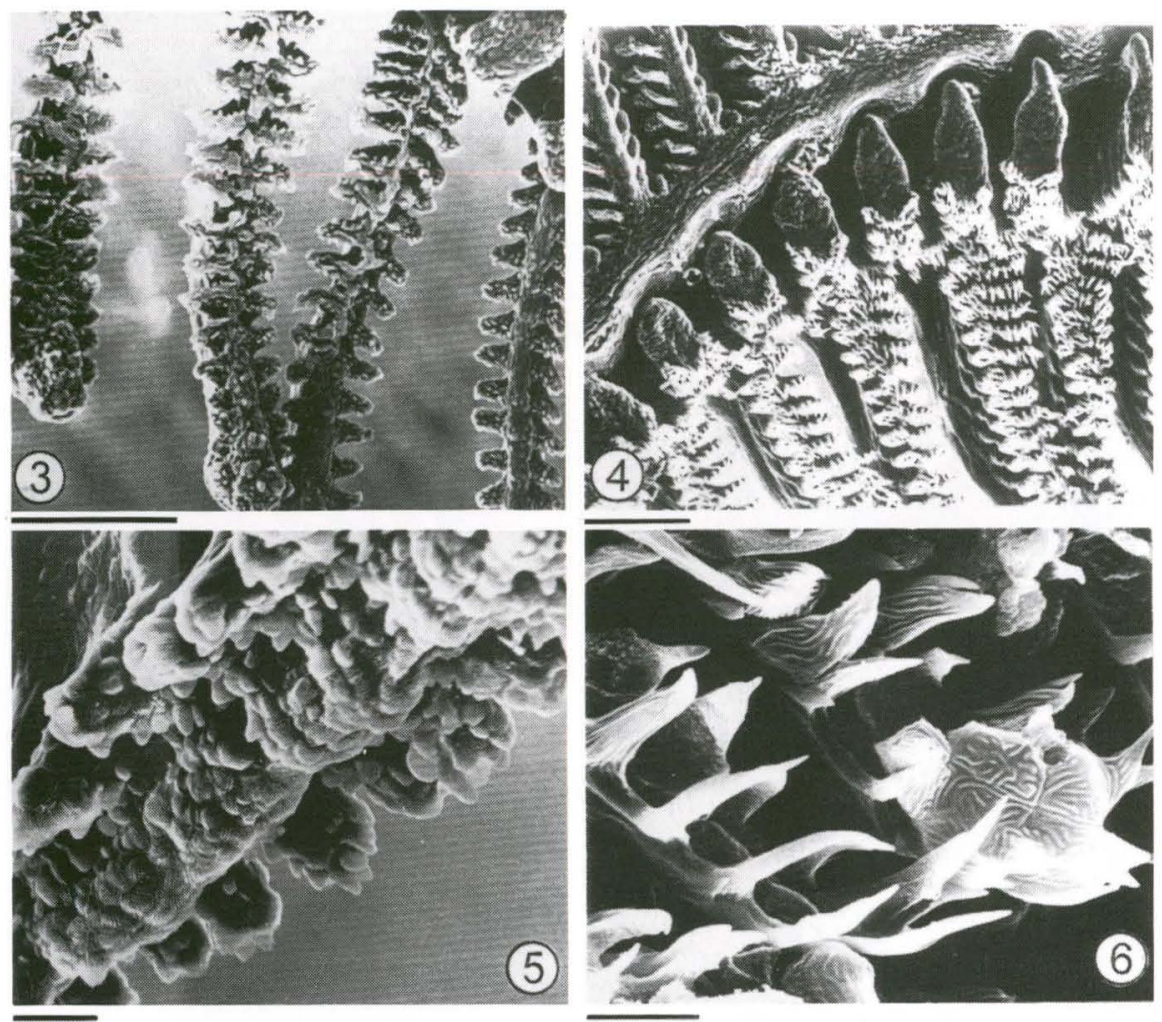

Figs 3-6. Eletromicrografias de rastelos branquiais do ABII esquerdo. (3) Região ventral apresentando projeções secundárias simples (notar a região de transição de simples para complexa, barra $=100 \mu \mathrm{m})$; (4) região dorsal apresentando projeções secundárias complexas $($ barra $=100 \mu \mathrm{m}) ;(5)$ detalhe das projeções simples (barra $=10 \mu \mathrm{m}) ;(6)$ detalhe das projeções secundárias complexas cobertas por células pavimentosas com micropregas (barra $=10 \mu \mathrm{m}$ ).

\section{Descrição geral dos filamentos}

O tamanho de cada filamento branquial varia ao longo dos arcos e hemibrânquias. Nos ABI, II e III a hemibrânquia medial é maior que a hemibrânquia lateral nas extremidades e em parte da região ventral, ocorrendo o oposto na região dorsal e em parte da região mediana dos arcos. Com relação ao tamanho dos filamentos, estes apresentam-se menores nas extremidades, aumentando progressivamente de tamanho em direção à porção mediana do arco. O ABIV apresenta a hemibrânquia lateral menor que a hemibrânquia medial em toda a sua extensão. Observa-se a intersecção dos pontos de inserção dos filamentos das hemibrânquias lateral e medial.

$\mathrm{O}$ número de filamentos entre os $\mathrm{ABII}$ esquerdo e direito não diferem significativamente nas mesmas regiões. Entretanto, o número de filamentos da hemibrânquia lateral foi significativamente maior do que o número de filamentos da hemibrânquia medial em um mesmo arco (Tabs I-II). 


\section{Descrição das lamelas respiratórias}

As lamelas respiratórias apresentam-se como estruturas achatadas, inseridas regularmente na posição transversal, de forma alternada e deslocadas mais para a região eferente nas regiões dorsal e ventral de cada filamento branquial. Na maior parte do filamento apresentam forma trapezoidal, passando para triangular na direção da região distal (Figs 7-10). Em cada lado do filamento estão presentes em média 37 lamelas respiratórias por milímetro.
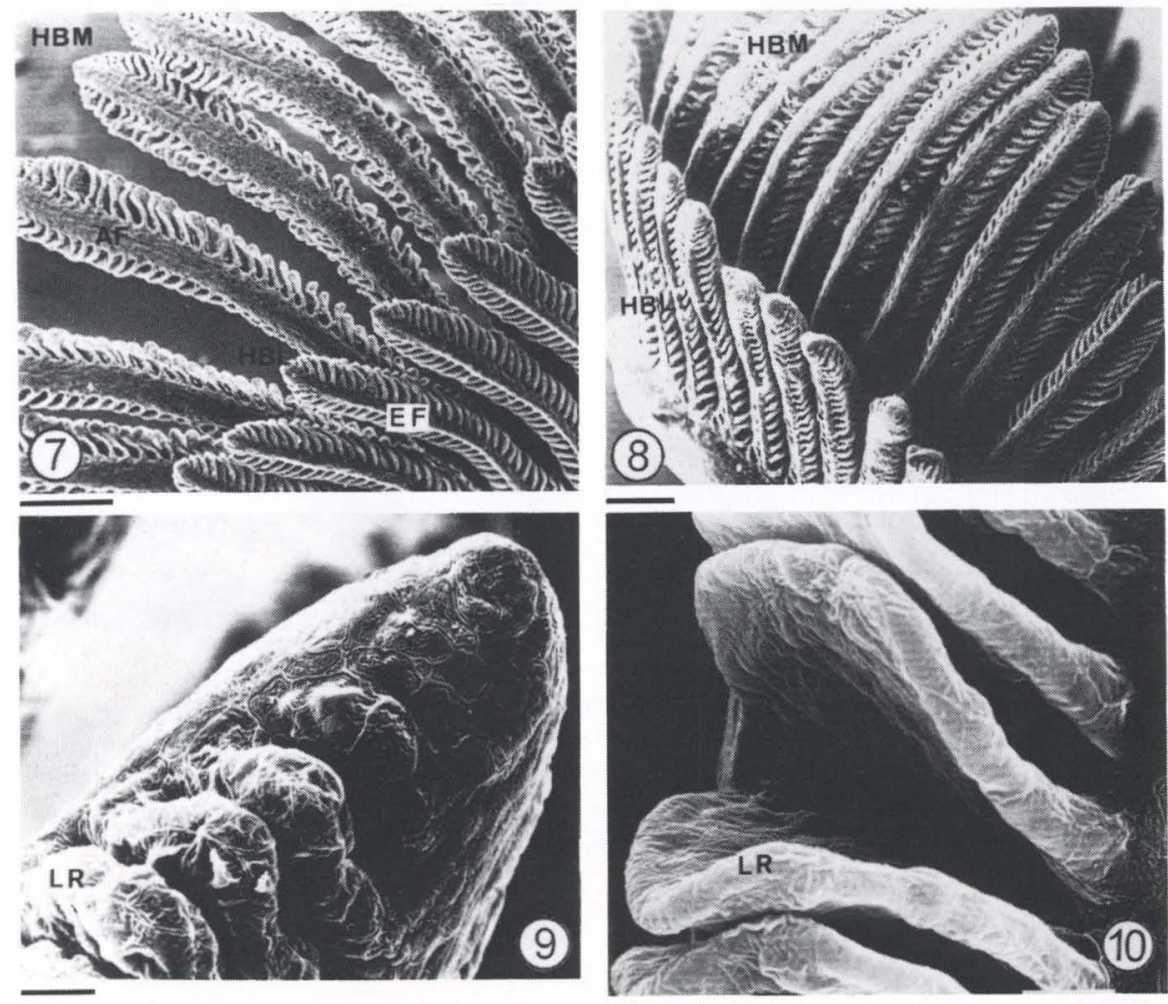

Figs 7-10. Eletronmicrografias dos filamentos do ABII esquerdo. (7) Vista geral das hemibrânquias medial (HBM) e lateral (HBL), mostrando a regiäo eferente (EF) e região aferente (AF) (barra $=100 \mu \mathrm{m}) ;(8)$ vista geral do arco mostrando as hemibrânquias lateral e medial (notar a curvatura côncavo-convexa do arco, barra $=100 \mu \mathrm{m}$; (9) detalhe das lamelas respiratórias (LR) da região distal do filamento (notar a forma triangular da lamela, barra $=10 \mu \mathrm{m}$ ); $(10)$ detalhe das lamelas respiratórias da região central do filamento (notar a forma trapezoidal e a ausência de micropregas sobre as células pavimentosas, barra $=10 \mu \mathrm{m}$ ).

\section{Descrição da ultraestrutura superficial do epitélio de revestimento do ABII}

O epitélio de revestimento de todo o ABII constitui-se de células pavimentosas poligonais dispostas em mosaico. As células pavimentosas apresentam o maior eixo em média com $6,71 \mu \mathrm{m}$ e o menor com $4,9 \mu \mathrm{m}$. 
Por toda a superfície destas células existem micropregas lineares com uma espessura variando de $0,1-0,2 \mu \mathrm{m}$, algumas vezes ramificadas, arranjadas concentricamente. Percorrendo todo o contorno externo da célula pavimentosa há uma microprega dando um nítido contorno para estas células (Fig. 11). Na região basal das lamelas respiratórias e na região interlamelar, as micropregas apresentam vários comprimentos, aparecendo em algumas partes punctiformes. As micropregas estão ausentes nas células pavimentosas que cobrem as lamelas respiratórias, dando um aspecto liso à membrana (Fig. 12).

Entre as bordas das células pavimentosas adjacentes foram observados poros com formatos irregulares. Os poros são evidenciados apenas na região aferente do filamento, nas bases das lamelas respiratórias e na região interlamelar não tendo sido observados na região eferente, nem sobre as lamelas respiratórias (Figs 13-14).
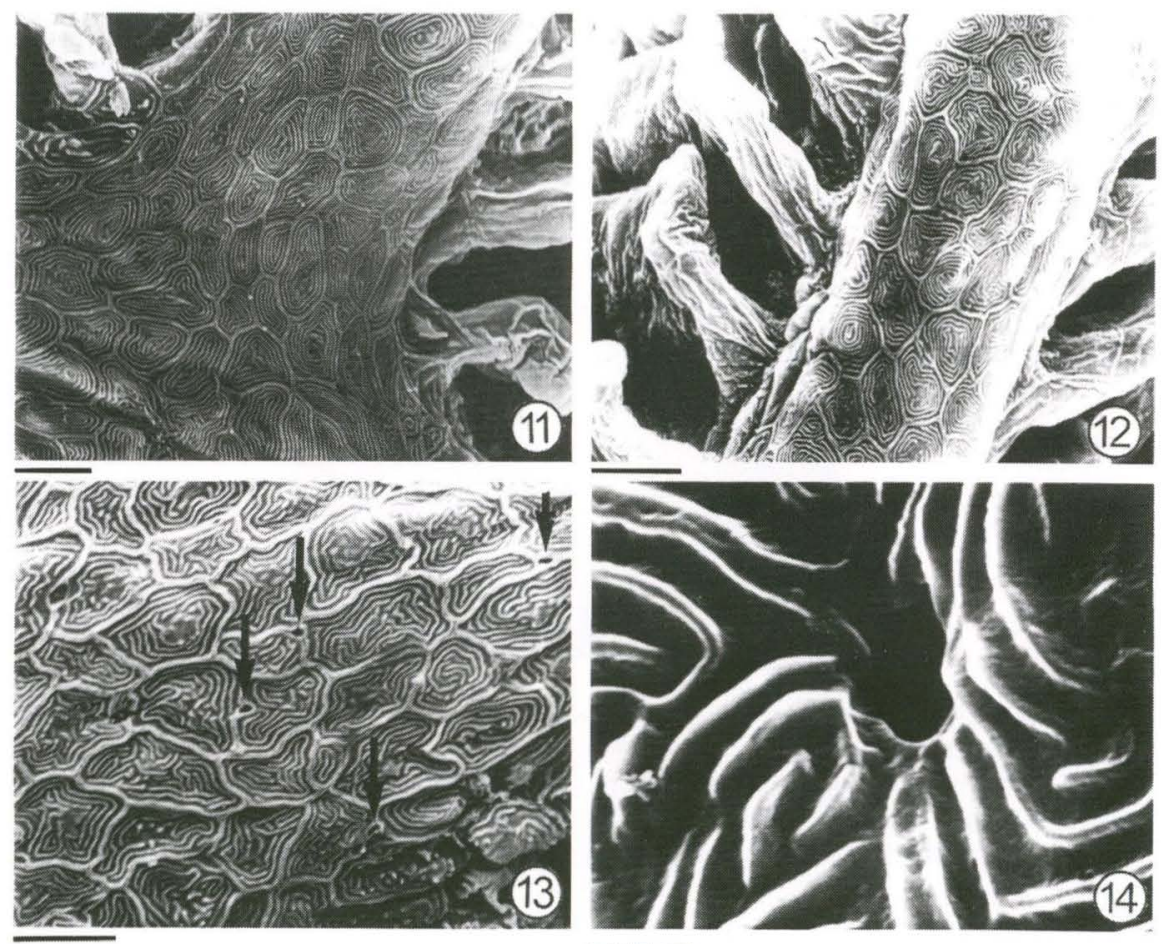

Figs 11-14. Eletromicrografias da superfície epitelial. (11) Vista da região lateral do ABII esquerdo ao nivel da inserção de um filamento (notar o nítido contorno das células pavimentosas e a transiçăo das micropregas em direção às lamelas respiratórias, barra $=10 \mu \mathrm{m}) ;(12)$ região eferente do filamento demonstrando a ausência de poros (barra $=10 \mu \mathrm{m})$; (13) região aferente do filamento mostrando a presença de poros das células de cloro (setas, barra = $10 \mu \mathrm{m}) ;(14)$ detalhe do poro da célula de cloro (barra $=1 \mu \mathrm{m})$. 
Toda a superfície do rastelo é coberta por células pavimentosas com micropregas, bem como as projeções secundária simples e complexas (Fig. 15). Entre as projeções secundárias simples, é evidenciado saliências regularmente espaçadas entre as células pavimentosas, contendo tufos de projeções microvilosas, (Figs 16-17). Estas saliências não foram observados entre as projeções secundárias complexas.

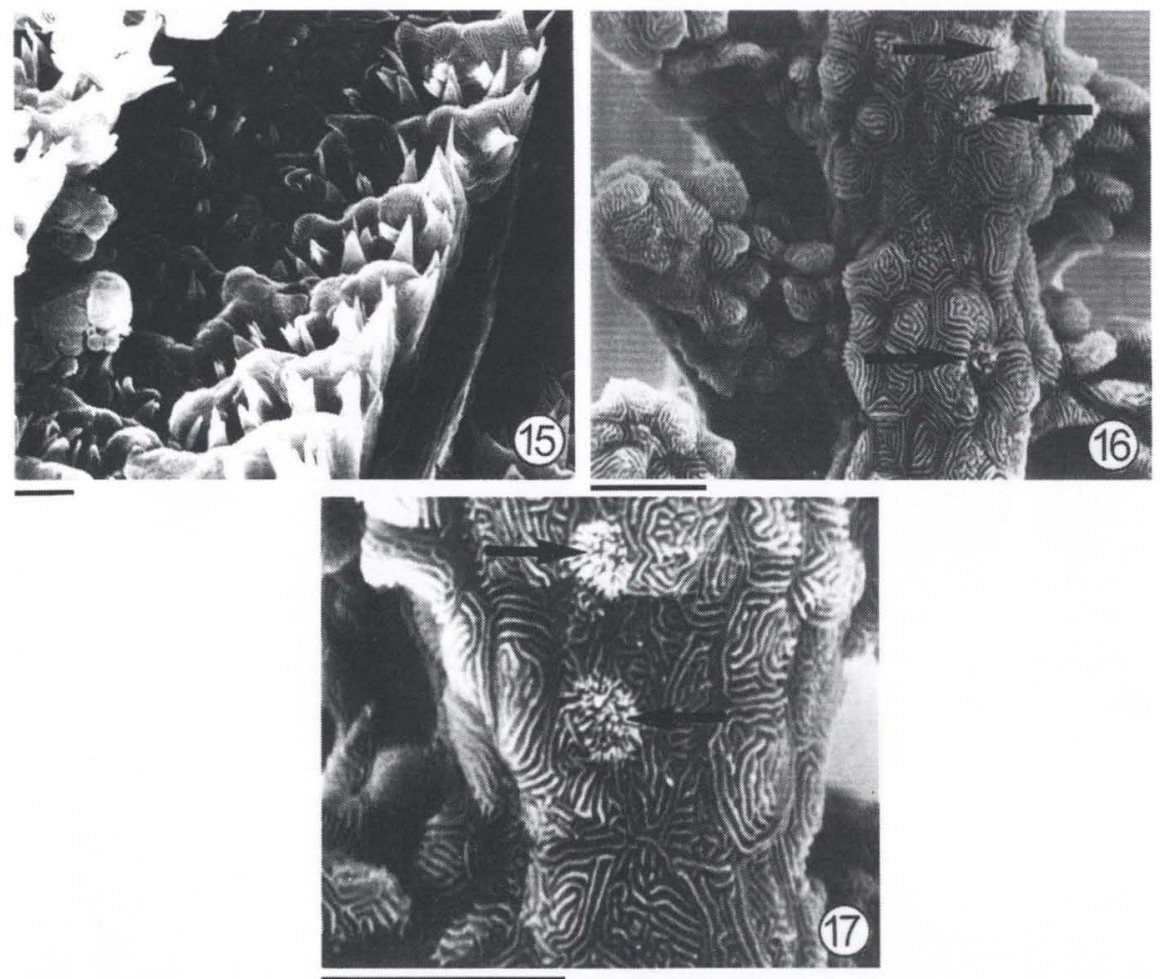

Figs 15-17. Eletromicrografias dos rastelos do ABII esquerdo com projeções secundárias cobertas com células pavimentosas com micropregas. (15) Projeções secundárias complexas (barra $=10 \mu \mathrm{m}) ;(16)$ projeções secundárias simples apresentando saliências com tufos de projeções microvilosas (setas, barra $=10 \mu \mathrm{m}$ ); $(17)$ detalhe dos tufos de projeções celulares (setas), na borda anterior do rastelo, entre as projeções secundárias simples (setas, barra = $10 \mu \mathrm{m})$.

\section{DISCUSSÃO}

Diferenças no número de rastelos entre regiões de um mesmo arco podem estar correlacionadas com o hábito alimentar da espécie ou até mesmo com o gênero (OJHA et al. 1987). Neste trabalho constatou-se em M. platanus a presença de um maior número de rastelos na fileira medial em comparação com a fileira lateral. A grande quantidade de rastelos alongados, próximos entre si e posicionados em 
direção à cavidade faringeal observados em $M$. platanus, são indicações de que a espécie é filtradora, e que obtém o alimento através de uma seleção passiva, retendo partículas pelos próprios rastelos ou por muco.

As projeções secundárias, presentes nos rastelos, foram observadas em diversas espécies de peixes, embora a sua função nos rastelos de mugilideos não esteja completamente compreendida. Porém as formas observadas parecem ser exclusivas de espécies da família Mugilidae (Hossler et al. 1979a,b; HoSSLER \& MERCHANT 1983). Projeções secundárias simples foram evidenciadas em todo o ABI e na região ventral do ABII dos juvenis de M. platanus. Tal como em Mugil cephalus Linnaeus, 1758 (HossLER \& MERCHANT 1983), os botões gustativos estão presentes no $\mathrm{ABII}$ exclusivamente na região entre as projeções secundárias simples. Embora não se tenha examinado a ultraestrutura do $\mathrm{ABI}$ de juvenis de $M$. platanus, a existência de projeções secundárias simples parece indicar a presença de botões gustativos também neste arco, o que parece ser bastante adequado ao processo de seleção de alimentos. Na espécie estudada, a presença de projeções secundárias simples em todo o $\mathrm{ABI}$ e na região ventral do $\mathrm{ABII}$, estaria relacionada com um processo seletivo menos eficiente de partículas pequenas, que constituem a maior parte da alimentação de peixes desta família (BRAGA 1982). Por outro lado, a presença de projeções secundárias complexas na região dorsal do $\mathrm{ABII}$ e em todo o ABIII e ABIV, estaria relacionada com a necessidade de um mecanismo de filtração mais eficiente, capaz de evitar que porções do material aglutinado atinjam e danifiquem as lamelas respiratórias.

O comprimento do filamento acompanha o crescimento do peixe e variações no comprimento deste podem ser observadas ao longo de uma hemibrânquia e entre hemibrânquias de um mesmo arco (HuGHes 1984). De maneira geral, encontram-se filamentos de tamanhos reduzidos nas extremidades do arco, que aumentam progressivamente de tamanho em direção à região mediana do arco. Em algumas espécies é observado um maior comprimento dos filamentos próximo ao terço superior do arco (HUGHES 1984). Uma variação mais comum observada em arcos de diversas espécies, é a presença de dois picos no comprimento do filamento, um geralmente situado na porção dorsal do arco e um segundo, maior, situado na porção ventral (HUGHES 1984). Este padrão pode ser observado somente no ABI dos juvenis de mugilídeos analisados. Nos demais arcos, o pico no comprimento foi evidenciado apenas na região ventral.

A variação no comprimento dos filamentos em uma mesma hemibrânquia e entre hemibrânquias do ABII encontrada nos juvenis de $M$. platanus analisados, foi a mesma encontrada nos ABII das espécies de mugilídeos estudados por OJHA et al. (1987), podendo esta característica, ser específica para a família. Segundo Hughes (1984), existe uma diferença no comprimento do filamento entre as hemibrânquias de um mesmo arco. Este autor observou que nos ABI e II de algumas espécies, os filamentos da hemibrânquia medial são usualmente maiores que os da hemibrânquia lateral. Nos juvenis de M. platanus, esta configuração foi apresentada apenas pelo ABIV. Nos demais arcos, a hemibrânquia medial foi maior que a lateral, somente na região mediano-dorsal, sendo que nas outras áreas, os filamentos da hemibrânquia lateral passam a ser maiores. HUGHES et al. (1984), estudando 
Scyliorhynus stellaris, constataram que as diferenças no comprimento do filamento estão correlacionadas com a orientação do sistema do arco branquial e serve para assegurar a justaposição correta das extremidades dos filamentos das duas hemibrânquias em um dado arco, fato que também pode explicar a variação no tamanho dos filamentos entre os arcos de juvenis de M. platanus.

A alternância encontrada entre as bases de inserção dos filamentos das hemibrânquias lateral e medial nos arcos branquiais de peixes, faz com que o número de filamentos em uma dada hemibrânquia seja sempre diferente da outra (HUGHES 1984), fato que explicaria a diferença encontrada entre as hemibrânquias do ABII de juvenis de $M$. platanus examinados neste trabalho. O número significativamente maior de filamentos na hemibrânquia lateral pode estar correlacionada à curvatura côncavo-convexa apresentada pelos arcos, onde a maior área proporcionada pela convexidade da região lateral permite a inserção de um maior número de filamentos, quando comparada a área proporcionada pela concavidade da região medial.

Entre as espécies de peixes são óbvias as diferenças com relação ao tamanho e o número das lamelas respiratórias (HUGHES 1984). A dimensão e forma das lamelas varia com a posição ao longo de cada filamento, e está associada, provavelmente, ao melhor aproveitamento da água de ventilação (HUGHES 1984). A freqüência e o tamanho das lamelas determina a área respiratória branquial, que varia consideravelmente com a atividade do peixe (GRAY 1954). O número médio de lamelas por milímetro de filamento branquial, observado no presente trabalho em juvenis de M. platanus, é típico dos peixes de atividade intermediária (GRAY 1954; HugHES 1984). Nestes juvenis de $M$. platanus as lamelas são numerosas e de tamanho médio quando comparadas com outro teleósteo de atividade intermediária, como M. cephalus (Hossler et al. 1979b). Por outro lado, a maior freqüência de lamelas por milímetro observada neste trabalho nos juvenis de $M$. platanus, em comparação com os valores médios (18-25) registrados por HUGHES (1984) para peixes de atividade intermediária, pode ser uma indicação de que a espécie estudada esteja mais próxima do grupo de peixes mais ativos, ou que simplesmente esta maior freqüência tenha relação com o estágio de desenvolvimento do peixe, ou com a espécie.

Neste trabalho, o segundo arco branquial (ABII) de jovens de M. platanus, apresentou células pavimentosas com micropregas cobrindo arcos, rastelos e suas projeções secundárias e filamentos, não aparecendo sobre as lamelas respiratórias. Várias são as funções atribuídas às micropregas. OJHA et al. (1987), sugerem que as micropregas geram microturbulências na água, aumentando o tempo de contato da água com o epitélio, permitindo uma maior difusão de oxigênio para o tecido. No entanto, é mais aceita a idéia de que esta estrutura estaria atuando em conjunto com os epitélios secretores, facilitando a fixação e difusão do muco sobre as células pavimentosas (SPERRY \& WASSERSUG 1977). Embora não se tenha observado poros de células secretoras de muco nos ABII de M. platanus, estruturas celulares muito bem documentadas em mugilideos (Hossler et al. 1979a,b; Hossler \& MERCHANT 1983), provavelmente também nesta espécie as micropregas estariam funcionalmente associadas à secreção de muco. 
Foram observadas micropregas com diferentes comprimentos nas células pavimentosas do epitélio branquial primário de M. platanus. Margeando as células, estão presentes micropregas longas e contínuas formando um nítido contorno, micropregas curtas ou sob a forma de traço predominam sobre a membrana, sendo em forma de traço e de ponto nas proximidades e entre as lamelas. Além da possibilidade de tais padrões de variação no tamanho das micropregas serem característicos de espécie (LAURENT 1984; OJHA et al. 1987), a presença de micropregas pequenas e pontuadas ao redor das lamelas de M. platanus, concorda com a afirmação feita por HUGHES (1979) de que estas estruturas parecem estar sempre associadas a regiões onde o fluxo de água é mais rápido.

As micropregas não foram observadas nas lamelas respiratórias dos juvenis de $M$. platanus, assim como em exemplares maiores de M. cephalus (HOSSLER et al. 1979a,b). A presença de micropregas nas lamelas, provavelmente aumentaria a distância entre o sangue e a água pela presença da camada de muco (OJHA et al. 1987), ou permitiria que partículas ficassem aderidas, dificultando as trocas gasosas. No entanto, micropregas foram observadas nas lamelas de Salmo gairdneri Linnaeus, 1758 (Hughes 1979) e Oncorhynchus nerka Walbaum, 1792 (FRANKLIN 1990).

A presença de micropregas nas projeções secundárias dos rastelos e na área entre estas projeções, em juvenis de $M$. platanus, difere do observado em $M$. cephalus (HOSSLER et al. 1979a,b). É provável que esta presença conjuntamente com o muco, represente um aumento na eficiência de captação de alimentos, proteção da estrutura celular e no processo de difusão de água e íons através do epitélio branquial.

AGRADECIMENTOS. Agradecemos a CAPES, ao Centro de Estudos do Mar, Universidade Federal do Paraná (UFPR), ao Curso de Pós-Graduação em Zoologia, UFPR, ao Centro de Microscopia Eletrônica, UFPR, ao do Laboratório de Microscopia Eletrônica do Instituto de Física, Universidade de São Paulo.

\section{REFERÊNCIAS BIBLIOGRÁFICAS}

BRAGA, F.M. DE S. 1982. Variação no número de rastros branquiais entre espécies de Mugil Linnaeus (Mugilidae, Teleostei) do litoral brasileiro. Dusenia, Curitiba, 13 (2): 81-911.

DUNEL-ERB, S. \& P. LAURENT. 1980. Ultrastructure of marine teleost gill epithelia: SEM and TEM study of the chloride cell apical membrane. Jour. Morphol., New York, 165: 175-186.

FRANKLIN, C.E. 1990. Surface ultrastructural changes in the gills of sockeye salmon (Teleostei: Oncorhynchus nerka) during seawater ransfer. Comparation of sucessful and unsuccessful seawater adaptation. Jour. Morphol., New York, 206: 13-23.

GRAY, I.E. 1954. Comparative study of the gill area of marine fishes. Biol. Bull., New York, 107: 219-255.

HossLER, F.E.; J.R. RUBY \& T.D. MCWIWAIN. 1979a. The gill arch of the mullet, Mugil cephalus. I. surface ultrastructure. Jour. Exp. Zool., New York, 208: 
379-398.

1979b. The gill arch of the mullet, Mugil cephalus. II. Modification in surface ultrastructure and $\mathrm{Na}-\mathrm{K}-\mathrm{ATP}$ ase content during adaptation to various salinities. Jour. Exp. Zool., New York, 208: 399-406.

Hossler, F.E. \& L.H. Merchant. 1983. Morphology of taste buds on the gill archses of the mullet Mugil cephalus, and the Fundulus heteroclitus. Amer. Jour. Anat., New York, 166: 299-312.

Hughes, G.M. 1966. The dimension of the fish gills in relation to their function. Jour. Exp. Biol. 45: 177-195.

. 1979. Scanning electron microscopy of the respiratory surfaces of trout gills. Jour. Zool. 188: 443-453.

- 1984. General anatomy of the gills, p.1-72. In: W.S. HOAR \& D.J. Randall (Eds). Fish Physiology. New York, Academic Press, Vol. 10A.

HugheS, G.M.; S.F. PERRY \& PIIPER. 1984. Quantitative anatomy of the gills of the larger spotted dog fish (Scyliorhinus stellaris). Jour. Exp. Biol. 98: 277-288.

LAURENT, P. 1984. Gill internal morphology, p.73-183. In: W.S. HOAR \& D.J. Randall (Eds) Fish Physiology. New York, Academic Press, Vol. 10A.

LAURENT, P. \& S. DUNEL. 1980. Morphology of gill epithelia in fish. Amer. Jour. Physiol. 238: 174-159.

OJHA, J.; A.K. MiSHRA \& S.D. MUNSHI. 1987. Interspecific variations in the surface ultrastructure of gills of freshwater mullets. Japan. Jour. Ichthyol. 33 (4): 388-393.

SCHIMIDT-Nielsen, K. 1990. Animal Physiology-adaptation and environment. Cambridge, Cambridge Univ. Press, $4^{\text {th }}$ ed., 602p.

SNEDECOR, G.M. \& W.G. Cochran. 1980. Statistical methods. Iowa State Univ. Press, Iowa, $7^{\text {th }}$ ed., 507p.

SPERRY, D.G. \& R.J. WASSERSUG. 1977. A proposed function for microrridges on epithelial cells. Anat. Rec. 185: 253-258.

Recebido em 11.XII.1997; aceito em 12.IV.1999. 